\title{
Integrating Metamaterial Antenna Node and LiFi for Privacy Preserving Intelligent COVID-19 Hospital Patient Management
}

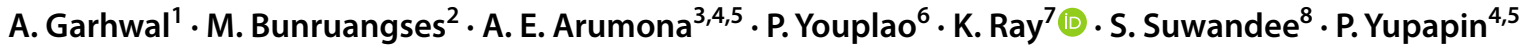

Received: 28 July 2020 / Accepted: 8 October 2020

(c) Springer Science+Business Media, LLC, part of Springer Nature 2021

\begin{abstract}
Light fidelity ( $\mathrm{LiFi}$ ) and wireless fidelity (WiFi) can be applied with the same network under the different constraints, which is suitable for COVID-19 surveillance in hospitals. The LiFi network is a high-capacity and security platform. A COVID-19 surveillance system using LiFi is proposed, which consists of two switching modes: communication and surveillance. Firstly, the communication targets are to accommodate the electromagnetic interference (EMI) immunity and high-capacity and security data transmission, where secondly the COVID-19 surveillance can be applied. In operation, the up and downlink system uses a metamaterial antenna embedded by Mach Zehnder interferometer (MZI). An antenna consists of silver bars embedded at the microring center with two-phase modulators at its sides. The entangled source namely a dark soliton is applied to form the transmission, where the information security based on quantum cryptography can be managed. By using the suitable parameters, the whispering gallery modes (WGMs) are generated and the up and downlink nodes are formed. The input information is multiplexed with time to form the multiplexed signals, where the big data transmission (40 $\mathrm{Pbit} \mathrm{s}^{-1}$ ) can be employed. By using the surveillance mode, the plasmonic antenna can be applied for temperature and electric force sensors, which can offer the disinfectant spray and temperature sensor for COVID-19 applications. The optimum plasma force sensitivity is $0.16 \mathrm{~N} \mathrm{~kg}^{-1} \mathrm{~mW}^{-1}$. The center frequencies of $191.48 \mathrm{THz}$ and $199.41 \mathrm{THz}$ are obtained for uplink and downlink antennas, respectively. The optimum temperature sensitivity is $0.05 \mathrm{rads}^{-1}{ }^{\circ} \mathrm{C}^{-1}$. In conclusion, the novelty of proposed work is that the integrated sensor circuits are employed for COVID-19 surveillance in the hospital. The fuzzybased system is designed for critical patient monitoring alert using this surveillance and management inside the hospital for COVID-19 patients.
\end{abstract}

Keywords COVID-19 surveillance $\cdot$ EMI network $\cdot$ Radio-over fiber link $\cdot$ LiFi $\cdot$ WiFi $\cdot$ Metamaterial antenna

\section{Introduction}

The coronavirus (COVID-19) started in December 2019 in Wuhan China. Then, it started spreading globally. World Health Organization (WHO) declared that this pandemic is a public health concern (PHC) globally.

\footnotetext{
Highlights

- No EMI, robust system

- Low latency, ultra high speed

- Data driven, cognitive, artificial management in hospital

- COVID-19 patient tracking

- Quantum security

K. Ray

kanadray00@gmail.com

P. Yupapin

preecha.yupapin@tdtu.edu.vn

Extended author information available on the last page of the article
}

It mainly affects the respiratory system of the human. COVID is similar to severe acute respiratory syndrome (SARS)-COV that occurred in 2003 and Middle East respiratory syndrome (MARS)-COV that occurred in 2012. The total number of confirmed coronavirus cases on 30th June is 10,429,791 according to World Health Organization (WHO) [1-3]. Work on vaccines is going on. Some vaccines are in the clinical trial stage. This disease spreads by a person-to-person transmission by droplets and aerosols. To control this, WHO has given some guidelines also for maintaining social distancing, using hand sanitizer, wearing masks, keeping isolation, etc. Washing hand frequently is recommended for hand hygiene. Mask will reduce the spread of droplets and aerosols, so it can prevent infecting other healthy people [4-6].The main protein structure of coronavirus is singlestranded RNA which is explained in detail along with the key events in COVID-19 outbreak [7]. Although for 
normal people, following the guidelines of WHO regarding social distancing is feasible, to maintain the social distancing is not that possible in hospitals. In hospitals, there are high chances that healthcare workers can easily get affected by coronavirus during treatment of patients $[8,9]$. Few papers are reported on the risk in connection to different types of treatments such as ophthalmology practice and oral-dental practice $[10,11]$. Now, to prevent the spread of virus inside the hospital among the doctors and staff, some surveillance system is required which will be controlled using LiFi (Light Fidelity) or WiFi (Wireless Fidelity) sensor nodes and where no EM (electromagnetic) interference with medical equipment occurs. Using a microring model, plasmonic op-amp circuit for pumping scheme has been presented. This has applications in LiFi up downlink applications $[12,13]$. Plasmonic antenna for LiFi and WiFi was also presented where the spin wave was generated using MZI. Two WGMs were observed for uplink and downlink communication. Plasmonic sensor node using the antenna for $\mathrm{LiFi}(\mathrm{WiFi})$ uplink and downlink is presented in the literature [14-16]. The virus can survive on dry surfaces also. A detailed comparative study was presented for SARS and MARS [17]. To kill the virus, silver (Ag) is a good disinfectant $[18,19]$. Along with the disinfectant, temperature sensors will also be required to monitor the temperature in hospitals. A patient temperature acquisition system using ZigBee wireless sensor network has been presented [20], from which the other wireless technologies along with ZigBee are WiFi, Bluetooth, and ultrawideband that have been integrated. Temperature sensors using MZI were also presented [21, 22]. Nowadays, hospitals are equipped with modern technologies, where the big data is also playing an important role in healthcare. By using the big data, doctor analyzes the patient's medical history, lifestyle, and according to that the more optimized treatment can be done, where the huge data is managed using artificial intelligence (AI) and advanced software $[23,24]$. The integrated e-healthcare system to monitor the health and real-time data using the biomedical data acquisition can be applied. It is suitable for elderly people telemedicine using the WiFi, Bluetooth, or wired link [25], where the electronic health record maintains the patient's data electronically. Other data sources are public health records and clinical data. But the main challenge in using big data is a patient's data security [26]. The patient data can be secured using quantum communication [27, 28]. Recently, the patient's medical diagnosis report also can be secured using quantum encryption and decryption method on the cloud [29]. The proposed system is a realistic feature, which can be implemented in the hospital area for future surveillance applications. In this work, metamaterial antenna using silver bar-embedded microring resonator is proposed for the COVID-19 surveillance network system. This type of antenna has been designed and well described in reference [30]. The proposed system uses the metamaterial antennas embedded MZI to form the up and downlink nodes for $\mathrm{LiFi}(\mathrm{WiFi})$ transmission network. This information transmits via the fiber optic cable and free space to detect COVID-19 medical parameters in hospitals with EMI immunity. The WiFi network can be applied in the certain location. In addition, the system provides high capacity and security using big data and quantum cryptography transmission schemes. The proposed microring circuit is designed with the Optiwave FDTD program and simulated with the formation of the whispering gallery mode (WGM) at the microring center, where the extracted parameters from the simulation results of the Optiwave FDTD are employed. The simulation result is validated by the Matlab program, where the results obtained are presented and discussed for dried plasma spray, uplink and downlink antenna profiles, quantum transmission, and temperature sensor, respectively. Finally, using the integrated LiFi networks is also discussed for the potential of COVID-19 surveillance applications.

\section{Methods}

The input signal is the dark soliton where the fabrication structure and its application for sensor circuit are shown in Fig. 1. The input signal divides into two equal parts using Mach Zehnder Interferometer (MZI). The MZI works as a 50:50 coupler. The center microring has two phase modulators (small rings) at its sides with two silver bars at the microring center.

The input dark soliton $\left(E_{\text {in }}\right)$ is given as [31]:

$E_{\text {in }}=\operatorname{Ctanh}\left[\frac{T}{T_{0}}\right] \exp \left[\frac{d}{2 L_{\mathrm{D}}}\right]$

Where $C$ is the optical field amplitude and $d$ is the propagation distance. $T$ is the soliton pulse propagation time in a frame moving with group velocity, $T=t-\beta_{1} \mathrm{z}$ where $\beta_{1}$ and $\beta_{2}$ are the coefficients of linear and second-order terms of the Taylor expansion of propagation constant. The dispersion length of the soliton pulse is denoted by $L_{\mathrm{D}}$ and given as $L_{\mathrm{D}}=\frac{T_{0}^{2}}{\beta_{2}}$, where $T_{0}$ is the initial propagation time.

The multiplexed space-time source applied to the system, which is expressed by:

$E_{\text {add }=} B \times e^{ \pm i \omega t}$ 
Fig. 1 Silicon microring embedded silver bar circuit for LiFi network up and downlinks, where (a) fabrication structure, (b) sensor circuits. The optical fields of the input, throughput, drop, and add ports are $E_{\mathrm{in}}, E_{\mathrm{th}}$, $E_{\mathrm{dr}}$, and $E_{\text {add }}$, respectively. $\kappa$ is coupling constants, Ag: silver bars, $R_{1}$ : center ring radius, $R_{2}$ : side ring radius. PBS: polarizing beamsplitter, PD: photodetector. $\mathrm{IV}>$ and $\mathrm{IH}>$ are the vertical and horizontal polarization components, respectively. The optical isolator is applied to protect the source feedback interference (a)

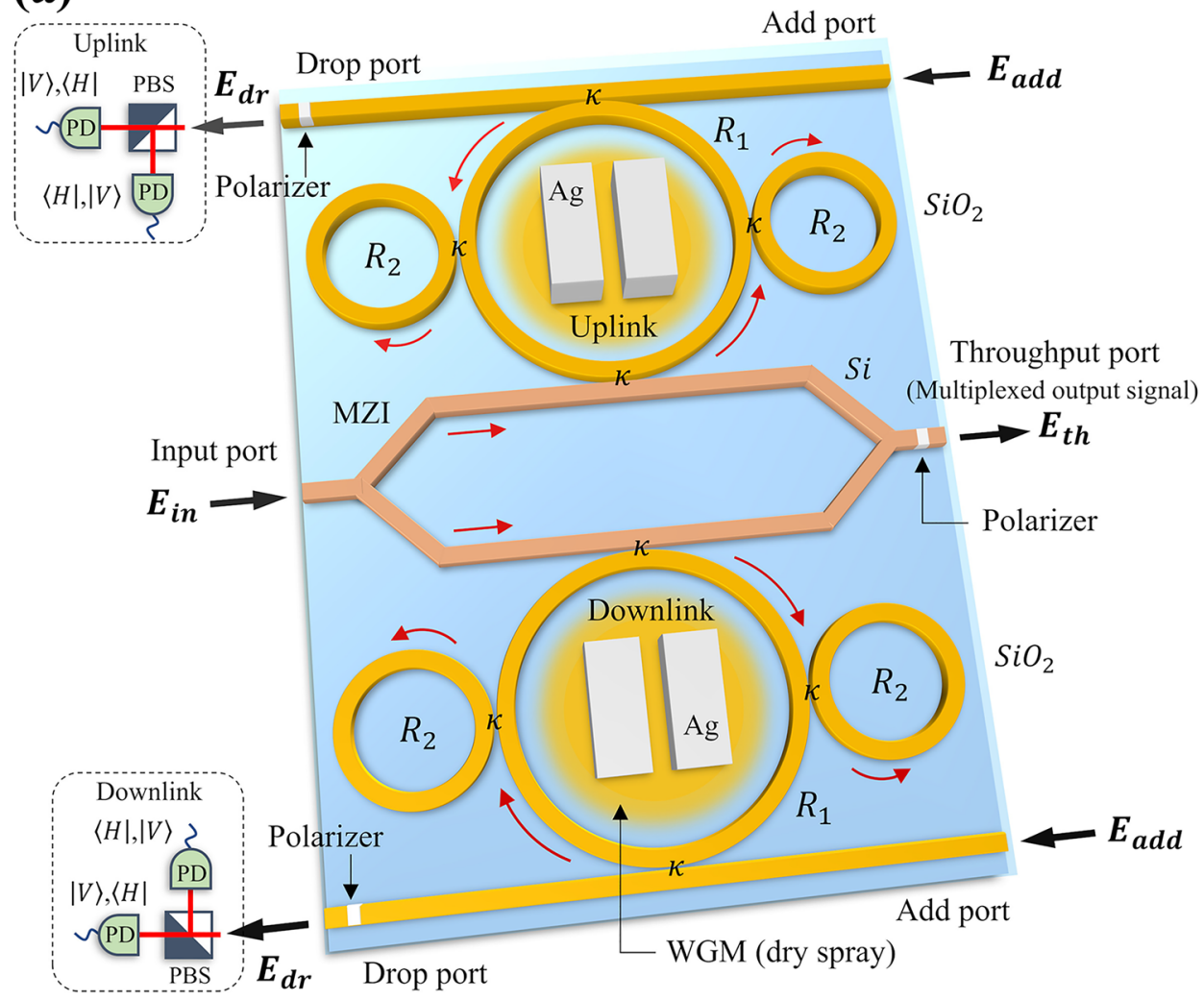

(b)

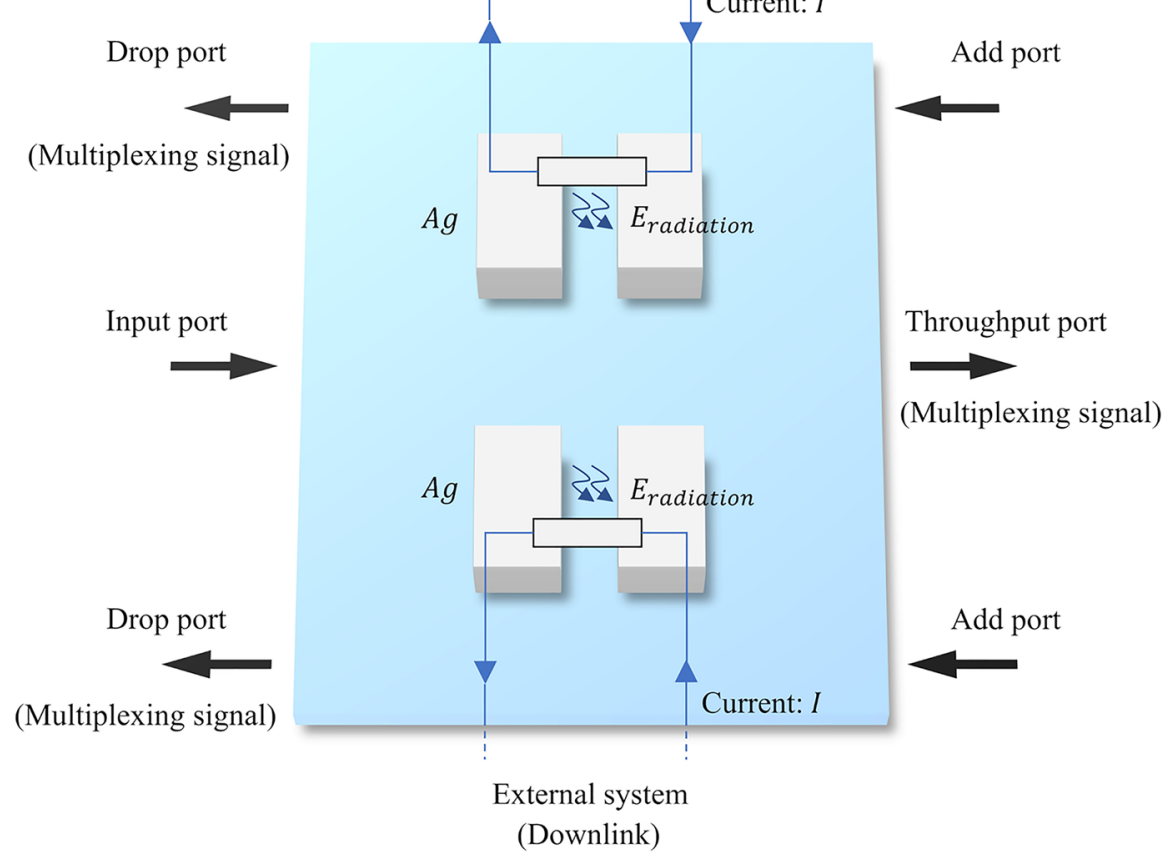


where $\omega=2 \pi f, f=\frac{c}{\lambda}, \omega, f$, and $c$ are the angular frequency, linear frequency, and speed of light in vacuum, respectively. $B$ and $t$ are the amplitude and time, respectively. \pm signs of the exponent term are used for the full-time slot axis; the control time is given by $e^{ \pm i w t}$, and $t=0$ for the time domain. The nonlinear effect is given as $n=n_{0}+n_{2} I=n_{0}+n_{2} P / A_{\text {eff }}$, where $n_{0}$ and $n_{2}$ are defined as the linear and nonlinear refractive indices, $I$ and $A_{\text {eff }}$ are the intensity and the effective core of the waveguide, respectively. The center ring is embedded with a bar of metamaterial silver. The behavior of electrons is described by Drude model [32]:

$\epsilon(\omega)=1-\frac{n_{\mathrm{e}} q^{2}}{\epsilon_{0} m \omega^{2}}$

where $n_{\mathrm{e}}, q, \epsilon_{0}$, and $m$ are the electron density, electron charge, permittivity of free space, and mass of an electron, respectively. $\omega$ is an angular frequency. The plasma frequency is given as:

$\omega_{\mathrm{p}}=1 / \sqrt{\frac{n_{\mathrm{e}} q^{2}}{\epsilon_{0} m}}$

From Eq. (3), the electron density becomes $n_{\mathrm{e}}=\frac{\omega_{\mathrm{p}}^{2} \epsilon_{0} m}{q^{2}}$.

The system output is given as [32]:

$E_{\mathrm{th}}=m_{2} E_{\mathrm{in}}+m_{3} E_{\mathrm{add}}$

$E_{\mathrm{dr}}=m_{5} E_{\mathrm{add}}+m_{6} E_{\mathrm{in}}$

where $m_{2}, m_{3}, m_{5}, m_{6}$ are constants defined and explained in $[32,33]$.

The system output is normalized intensities given as:

$\frac{I_{\mathrm{th}}}{I_{\mathrm{in}}}=\left[\frac{E_{\mathrm{th}}}{E_{\mathrm{in}}}\right]^{2}$

$\frac{I_{\mathrm{dr}}}{I_{\text {in }}}=\left[\frac{E_{\mathrm{dr}}}{E_{\text {in }}}\right]^{2}$

When light propagates within a circular motion path, the projection forms the particle oscillation. The particle (electron cloud) motion related to the force $(F)$ is given by an Eq. (9).

$F=m a=m \omega^{2} r=m(2 \pi f)^{2} r$

where $f, r, a$, and $m$ are the electron cloud plasma frequency, microring radius $\left(R_{1}\right)$, acceleration, and mass of an electron. This is the force required for dried spray particles to move.

The change in temperature $(\Delta T)$ is given as [33]:
$\Delta T=\frac{P d_{\text {silver }}}{K_{\mathrm{Ag}} A}$

where $P$ is defined as the input power, $K_{\mathrm{Ag}}$ is defined as the thermal conductivity of silver bar, $A$ is the area of silver bar, and $d_{\text {silver }}$ is the thickness of silver film.

From Fig. 1, the quantum cryptography is formed by the polarizing beamsplitter arrangement, from which the quantum bits can be obtained for security requirement. $H$ and $V$ present the horizontal and vertical polarized light components, respectively. The quantum codes (bits) between the sender and receiver can be confirmed by the classical communication channel in the LiFi network, which can support the medical data security requirement.

The functional block diagram is shown in Fig. 2. The system infrastructure consists of metamaterial antenna which provides wider bandwidth and communicates between patient's device and doctor's mobile. Antenna uses Li-Fi and Wi-Fi for communication. Fuzzy logic controller makes the smart decisions for patients and sends notifications to doctors.

\section{Results}

The system is designed in optiFDTD simulation software [34]. The grid size for simulating the structure is automatically implemented by the optiFDTD software. The input signal is a dark soliton of $1.55 \mu \mathrm{m}$ wavelength. The input signal is applied at the input port $\left(E_{\text {in }}\right)$ of the system. The schematic diagram and fabrication structure are shown in Fig. 1a, b. The center is embedded with a silver metamaterial bar. Silver bars have a length and width of $1.25 \mu \mathrm{m}$ and $2.0 \mu \mathrm{m}$, respectively. The MZI material is silicon. The material of panda ring resonator is silica $\left(\mathrm{SiO}_{2}\right)$. The length and width of the structure are $15 \mu \mathrm{m}$ and $13 \mu \mathrm{m}$, respectively. The system has a center ring $\left(R_{1}\right)$ and two smaller side rings $\left(R_{2}\right)$ on the left and the right sides. The center microring radius is $2 \mu \mathrm{m}$ and side ring radius is $0.8 \mu \mathrm{m}$. The dark soliton as given in Eq. (1) is applied at the input port of the system (the system described in Eqs. (5) and (6)). The Drude model (as given in Eq. (3)) explains the behavior of electrons in the silver material when excited by the input signal. The design system is simulated for 20,000 steps in OptiFDTD to obtain resonant results. Table 1 gives the optimized parameters used in the simulation. Figure 3 shows the simulation results of OptiFDTD. The intensity plot is shown in Fig. 3a, where two WGMs are formed for uplink and downlink. WGM is formed by the trapping of light and electrons inside the microring. 


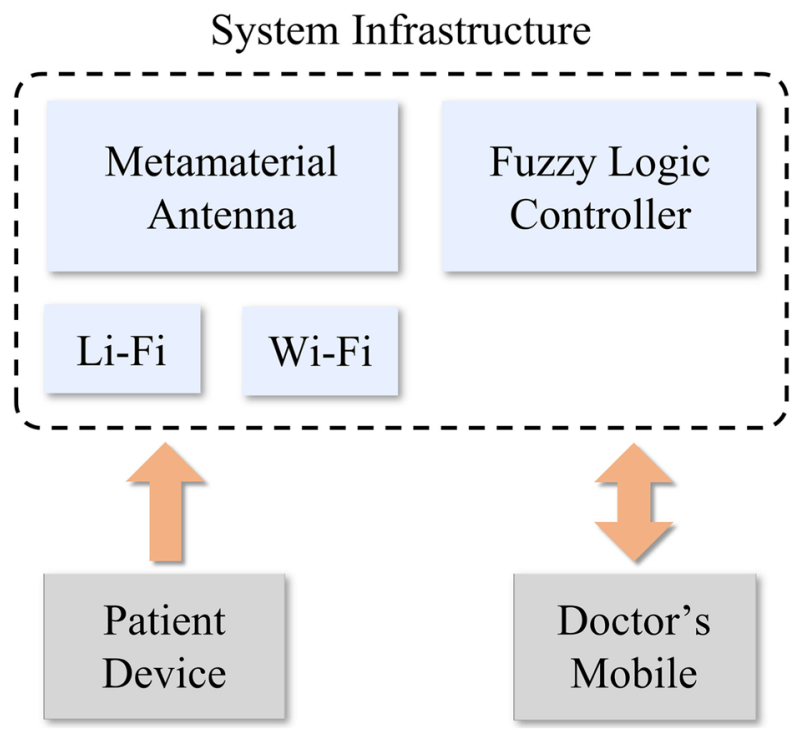

Fig. 2 Functional block diagram

Figure $3 \mathrm{~b}$ shows the trapped electron distribution. The WGM phenomenon is made possible by the nonlinearity effect induced in the system. The two-phase modulators (small rings) at the side of the center microring induce the nonlinearity effect. The WGM which is generated at the center ring provides the resonant optical path difference. The optical path difference matching is established by the two-phase modulators. The data from OptiFDTD is extracted and plotted using MATLAB software. The up and down WGMs form the antenna for uplink and downlink communications. Figure 4 shows the antenna profiles. Antenna gain is plotted by varying the input power from 40 to $50 \mathrm{~mW}$. The standard definition of antenna gain is used for plotting [14]. From Fig. 4a, the uplink gain is $4.95 \mathrm{~dB}$ and downlink gain is $1.28 \mathrm{~dB}$. The variation of gain with input power is almost linear. Uplink gain is more than downlink gain. Figures $4 \mathrm{~b}$ and $\mathrm{c}$ show the uplink and downlink directivity of 16.22 and 12.55, respectively. Figure $4 d$ shows the WiFi bandwidths. The uplink center frequency is $191.48 \mathrm{THz}$ with bandwidth of $14 \mathrm{THz}$ in the band 185.5-199.5 THz. Similarly, downlink center frequency is $199.41 \mathrm{THz}$ with bandwidth of $11 \mathrm{THz}$ in the band 193.5-204.5 THz. Uplink bandwidth is more than the downlink bandwidth. Figure 4e shows the LiFi bandwidths. The LiFi uplink center wavelength is $1.56 \mu \mathrm{m}$ with available bandwidth of $21.4 \mu \mathrm{m}$. The downlink center wavelength is $1.50 \mu \mathrm{m}$ with bandwidth of $27.4 \mu \mathrm{m}$. LiFi uses wavelength while WiFi uses frequency for the transmission. Figure 5 shows the intensity plot of dried spray. The intensity plot for frequency domain, wavelength, and time domain is shown in Fig. 5a-c. COVID-19 can survive on dry surfaces for
Table 1 The optimized parameters for simulation

\begin{tabular}{ll}
\hline Parameters & Values \\
\hline Input power $(\boldsymbol{P})$ & $40-50 \mathrm{~mW}$ \\
Input wavelength $(\lambda)$ & $1.55 \mu \mathrm{m}$ \\
Center ring radius $\left(\boldsymbol{R}_{1}\right)$ & $2.0 \mu \mathrm{m}$ \\
Small ring radius $\left(\boldsymbol{R}_{2}\right)$ & $0.80 \mu \mathrm{m}$ \\
Silver thermal conductivity $\left(\boldsymbol{K}_{\text {Ag }}\right)[36]$ & $406 \mathrm{Wm}^{-1} \mathrm{~K}^{-1}$ \\
Silver refractive index $\left(\boldsymbol{n}_{\text {Ag }}\right)[37]$ & 0.14 \\
Coupling coefficient $(\boldsymbol{\kappa})$ & 0.50 \\
Insertion loss $(\boldsymbol{\gamma})$ & $0.50 \mathrm{~dB}$ \\
Structure dimensions $(\boldsymbol{L} \times \boldsymbol{W})$ & $15 \times 13 \mu \mathrm{m}^{2}$ \\
Silver bar length $(\boldsymbol{L})$ & $1.25 \mu \mathrm{m}$ \\
Silver bar width $(\boldsymbol{W})$ & $2.0 \mu \mathrm{m}$ \\
Silica refractive index $\left(\boldsymbol{n}_{\text {sio }}\right)$ & 1.45 \\
Silica nonlinear refractive index $\left(\boldsymbol{n}_{2}\right)$ & $2.7 \times 10^{-16} \mathrm{~m}^{2} \mathrm{~W}^{-1}$ \\
Si refractive index $\left(\boldsymbol{n}_{\mathbf{s i}}\right)$ & 3.42 \\
Fiber loss & $0.1 \mathrm{dBkm}$ \\
Core effective area $\left(\boldsymbol{A}_{\text {eff }}\right)[38]$ & $0.30 \mu \mathrm{m}^{2}$ \\
Free space permittivity $\left(\boldsymbol{\epsilon}_{0}\right)$ & $8.85 \times 10^{-12} \mathrm{Fm}^{-1}$ \\
Electron mass $(\boldsymbol{m})$ & $9.11 \times 10^{-31} \mathrm{~kg}^{-1}$ \\
Electron charge $(\boldsymbol{q})$ & $1.60 \times 10^{-19} \mathrm{Coulomb}^{-1}$ \\
Waveguide loss $(\boldsymbol{\alpha})$ & $0.50 \mathrm{dBmm}$ \\
\hline
\end{tabular}

up to 9 days. Survival of COVID-19 on different dry surfaces are explained in [8]. There is a need for a spray to disinfect the surfaces. The use of silver $(\mathrm{Ag})$ nanoparticles as disinfectant has been explained in $[18,19]$. Figures $6 \mathrm{a}$ and $\mathrm{b}$ show the dried spray station in frequency and wavelength domain for both uplink and downlink. Figure $6 \mathrm{c}$ is the plot of the plasma force (as given in Eq. (9)) for both the uplink and downlink where the sensitivity of $0.14 \mathrm{~N} \mathrm{~kg}^{-1} \mathrm{~mW}^{-1}$ and $0.16 \mathrm{~N} \mathrm{~kg}^{-1} \mathrm{~mW}^{-1}$ is obtained, respectively. The frequency domain spray uses $\mathrm{WiFi}$ while the wavelength domain uses LiFi. The obtained plasma frequencies for uplink and downlink are $1.91 \times 10^{16} \mathrm{rad} \mathrm{s}^{-1}$ and $1.99 \times 10^{16} \mathrm{rad} \mathrm{s}^{-1}$, respectively. The installation of a spray station would be in one corner of the hospital. The patient, doctor, nurse, and anyone can go to that corner and get disinfected. There is no need for human interference. The dried spray generation is explained. The pumping of the spray (the working principle of the system) is based on the space-time distortion [35]. This spray is dried in nature. The use of this disinfectant will kill the virus. Figure 7 shows the multiplexed signal at the output of MZI. The input signal (dark soliton) is multiplexed with time at the add port $\left(E_{\text {add }}\right)$ to form the space-time function (as given in Eq. (2)) which excites the silver bar leading to electron cloud oscillation that forms the electron density resulting 

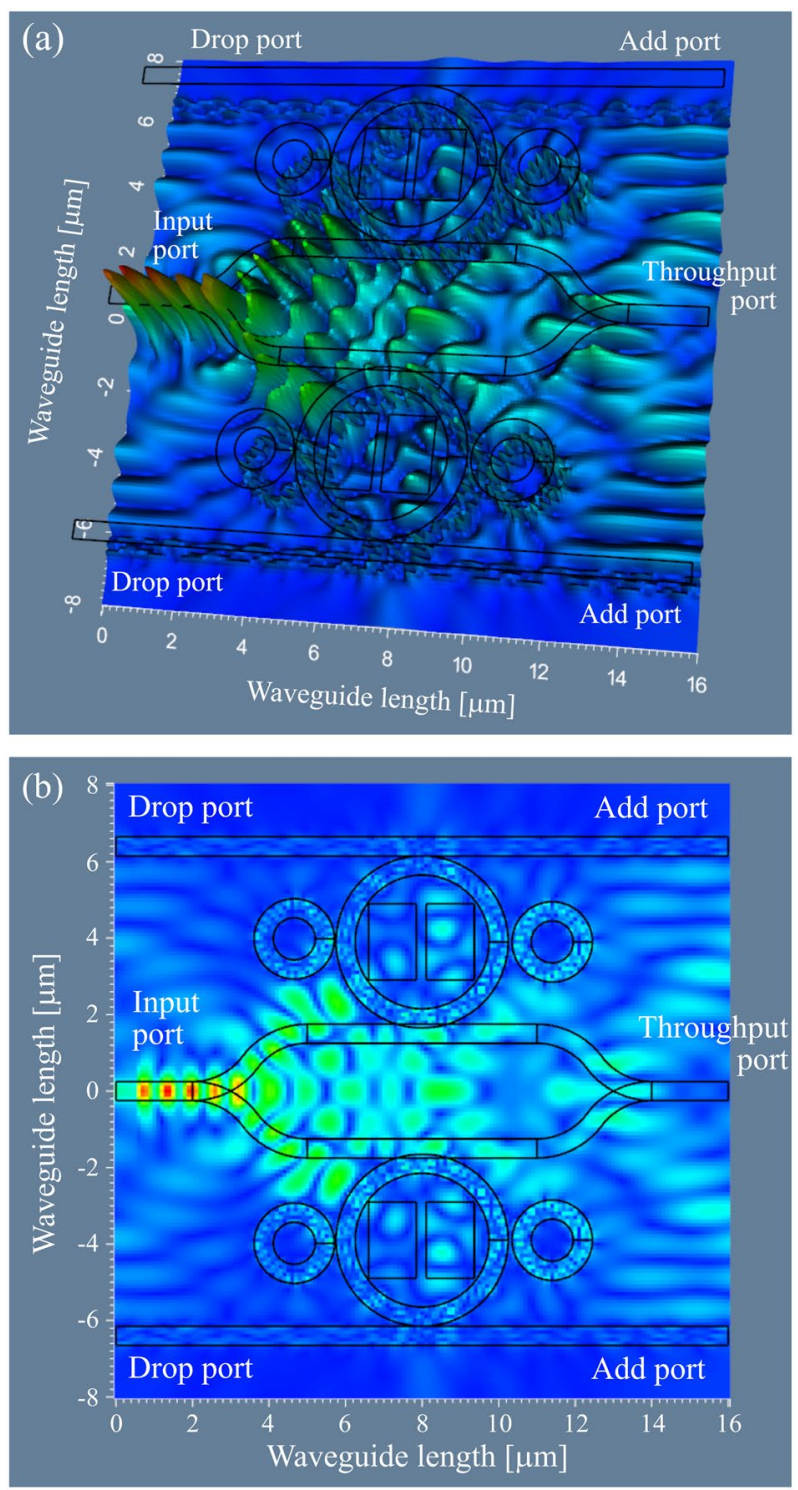

Fig. 3 The Optiwave FDTD graphical results, where (a) the intensity plot of the WGM formed at the center of the microring, (b) the electric field distribution within the up and downlink nodes. The used parameters are listed in Table 1

in the spin-up and down of electrons. At the system output, the spin-up of electrons at the Eth port and the spindown of electrons at the $E_{\mathrm{dr}}$ port, the obtained multiplexed bandwidth is $40 \mathrm{Pbits}^{-1}$. Figure 8 shows the plot of the plasma frequency and change in temperature which forms the temperature sensor (temperature checkpoint). The sensitivity of $0.04 \mathrm{rads}^{-1}{ }^{\circ} \mathrm{C}^{-1}$ and $0.05 \mathrm{rads}^{-1}{ }^{\circ} \mathrm{C}^{-1}$ is obtained, respectively, for the uplink and downlink. This checks the temperature of patients or staff who walk into the hospital. Figure 9 shows the uplink and downlink entanglement for security.
The spin up and down of electrons are entangled and can be used for quantum transmission of signals which provide better security during transmission and reception of the signal. Signal transmission and reception are achieved using WiFi and LiFi. Figures $9 \mathrm{a}$ and $\mathrm{b}$ show the entangled source for the uplink and downlink using WiFi, and Fig. 9c, d the entangled source for the uplink and downlink using LiFi. The plasmonic circuit produces quantum interference making use of entangled electrons with entangled photon source. The spin-up and spin-down result from electron cloud oscillation. This plasmonic circuit can be used for quantum code encryption as shown in Fig. 9. In the present paper, our attempt is to identify, connect, and integrate all the criteria required for overall intelligent hospital surveillance. Some descriptions about quantum security have also been given in [26, 27].

Figure 10 shows the EMI network and ad hoc surveillance and alarming in hospitals. Fiber opticLiFi (WiFi) network using big data transmission is applied for COVID-19 surveillance, where (a) in the hospital, (b) outside the hospital: the LiFi nodes are linked with the intensive care unit and fuzzy control as shown in Fig. 10b, in which the WiFi can also be available for optional connection in the EMI location such as in the conference room, outside the hospital, and others. From the up and downlink node, the electro-optic conversion signals can be formed by the transducer circuits, in which the plasmonic circuit namely the microring embedded silver bars are applied, from which the micro antenna, dried spray, force, and temperature sensors can be integrated with the fiberLiFi network, where the WiFi is the option in the case of EMI immunity not required. The dried spray electric force can be adjusted for each suitable case, which can be applied for hand cleaning in the required location. It is a dried spray without any replacement, which requires only the battery charger. The remote temperature checkpoint can be installed in any location, in which the remote temperature can be detected and reported. The alarm can also be linked with the critical case to the LiFi network. The LiFi and WiFi registration points are also available for personnel communication at the entrance nearby the registration point.

In Fig. 10, a $\mathrm{LiFi}(\mathrm{WiFi})$ network is applied for COVID-19 surveillance, where (a) shows the hospital, (b) the fuzzy alert, doctor's room, and server connection. The WiFi can also be available for optional connections in the EMI location. From the up and downlink nodes, the electro-optic conversion signals can be formed by the transducer circuit, which is the plasmonic circuit microring embedded silver bars, from which the micro antenna and dried spray are established. Besides, force 
Fig. 4 The plot of antenna profiles of the up and downlink nodes, where (a) the antenna gain, (b) the uplink directivity, (c) the downlink directivity, (d) the WiFi band with the uplink and downlink center frequencies of $191.48 \mathrm{THz}$ and $199.41 \mathrm{THz}$, respectively, (e) the Li-Fi band with the uplink and downlink center wavelengths of $1.56 \mu \mathrm{m}$ and $1.50 \mu \mathrm{m}$, respectively.

The multiplexed signals can be applied by the space-time modulation in both frequency and wavelength domains, from which the information capacity can be increased to accommodate the big data transmission
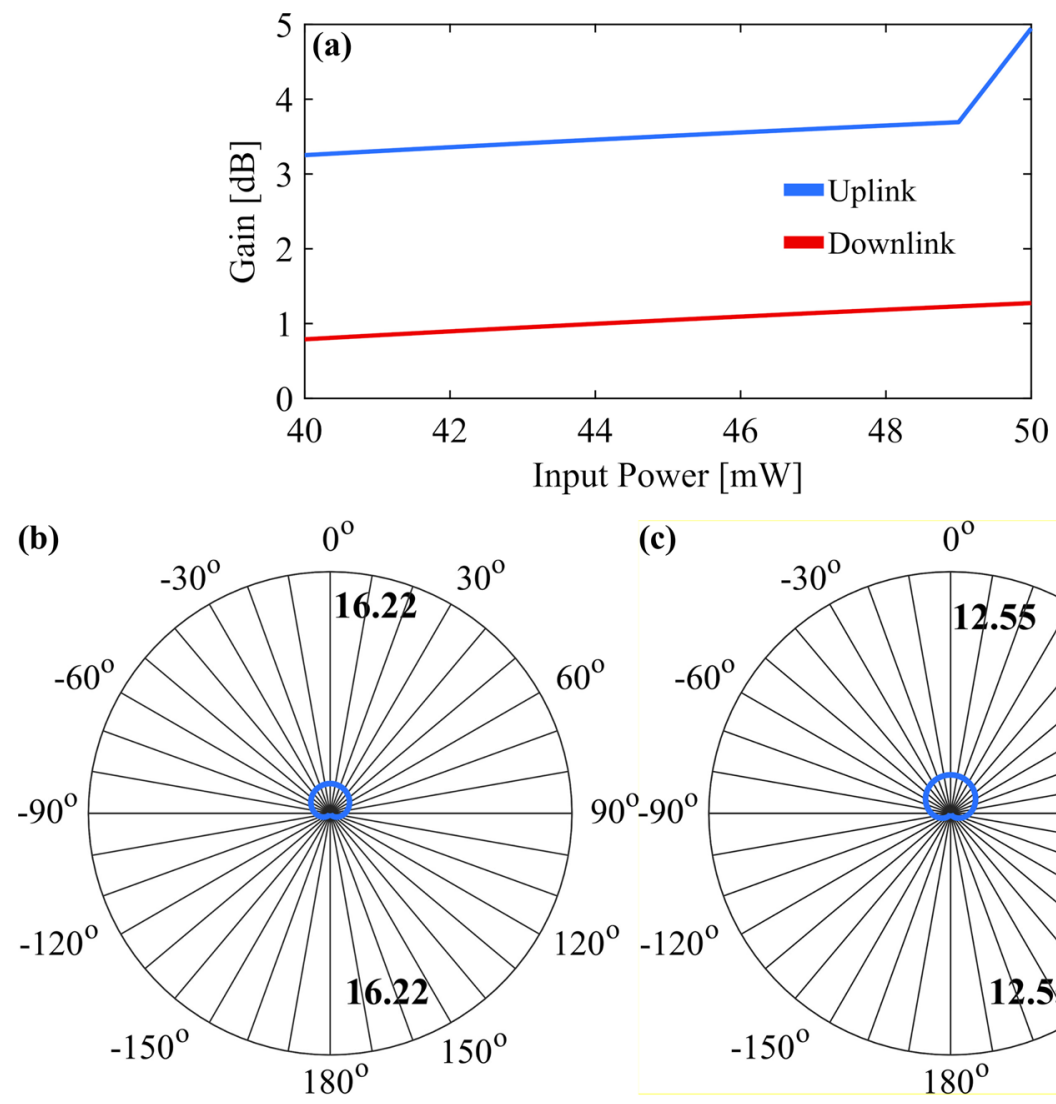

(c) $-30^{\circ}$
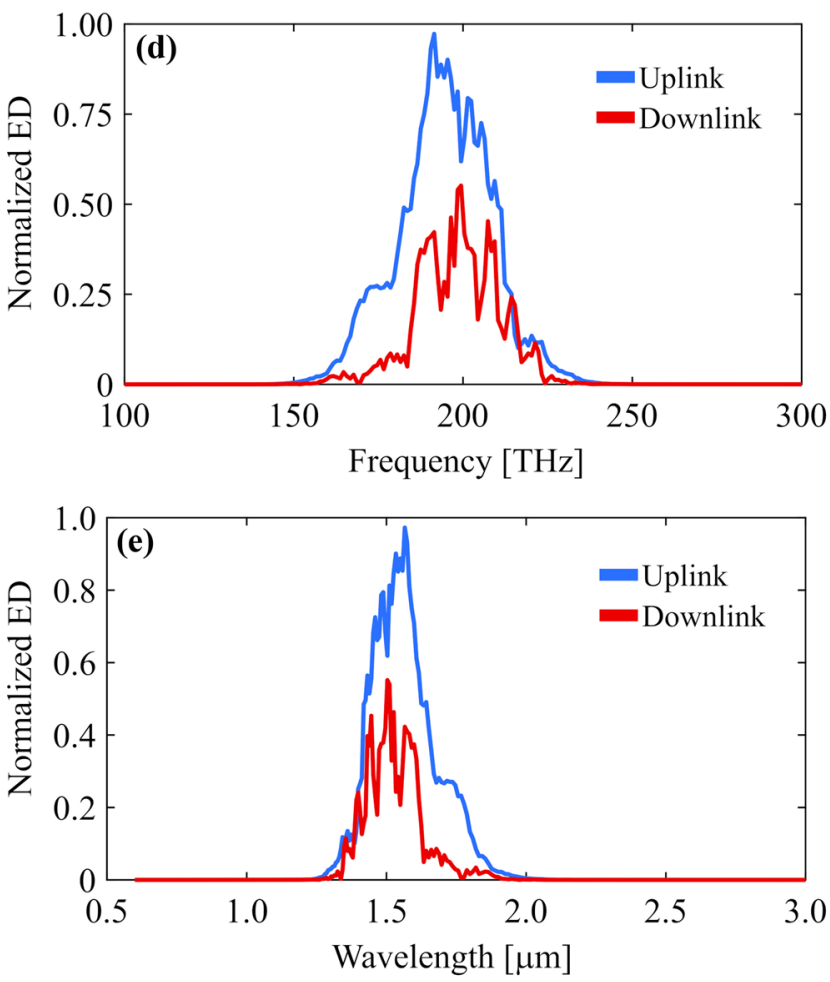

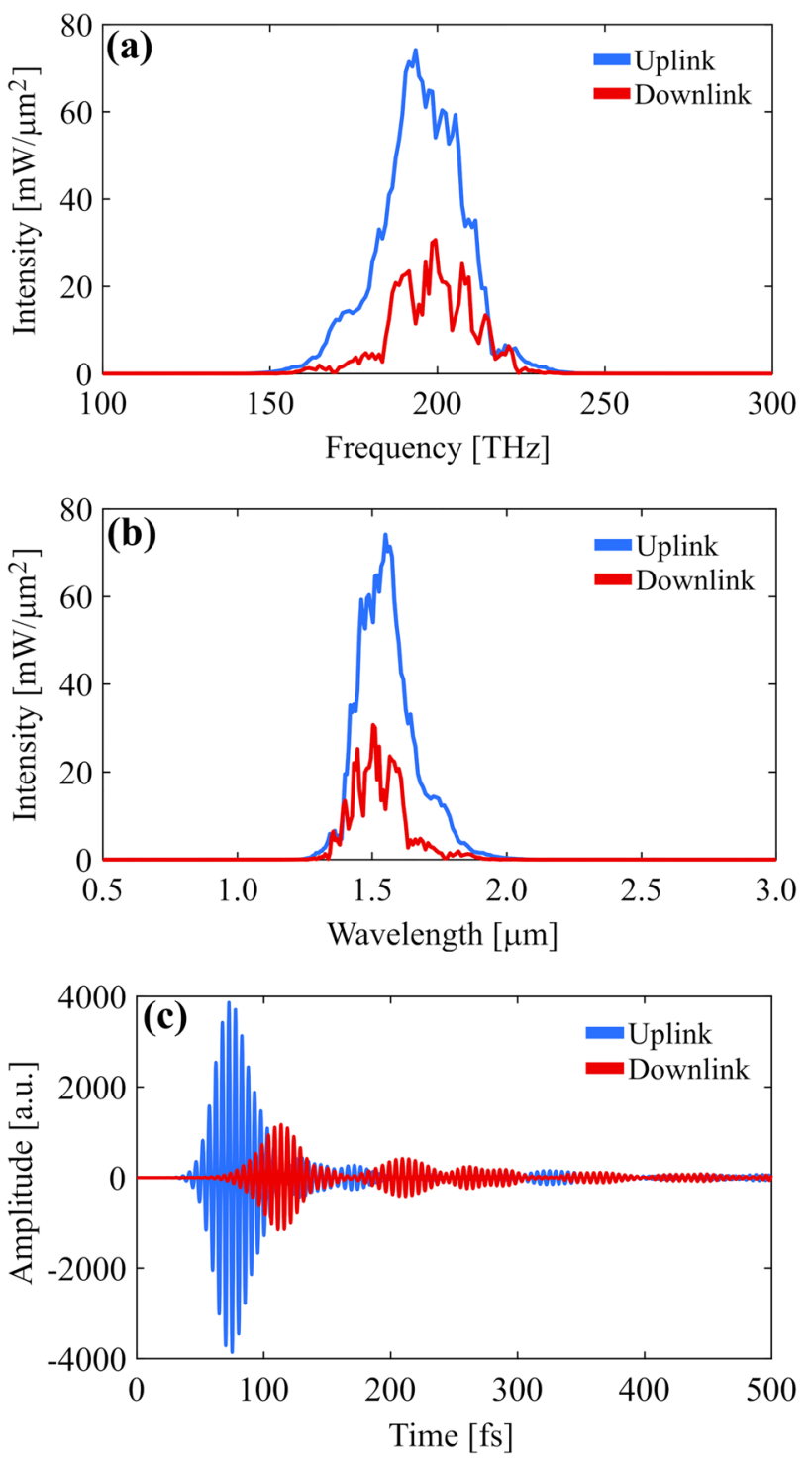

Fig. 5 The plot of the intensity outputs, where (a) frequency domain, (b) wavelength domain, (c) time domain, which are the plasma spray distributions of the up and downlink sensor nodes. By using the metamaterial results, the signal bandwidths are covered from light wave to radio wave frequencies. The system can support a fiber optic-radio transmission, where the exchange between radio wave and fiber optic signals can be performed by up and downlink nodes along the transmission lines

and temperature sensors can be formed and integrated with the fiber LiFi network. Dried spray force can be adjusted for each suitable case, which can be applied for hand cleaning in the required location. The dried spray is required only for the battery charger without any replacement. Remote temperature checkpoint can be installed in any location, which can be detected and realtime reported. The LiFi and WiFi registration points are also available for personal communication at the entrance
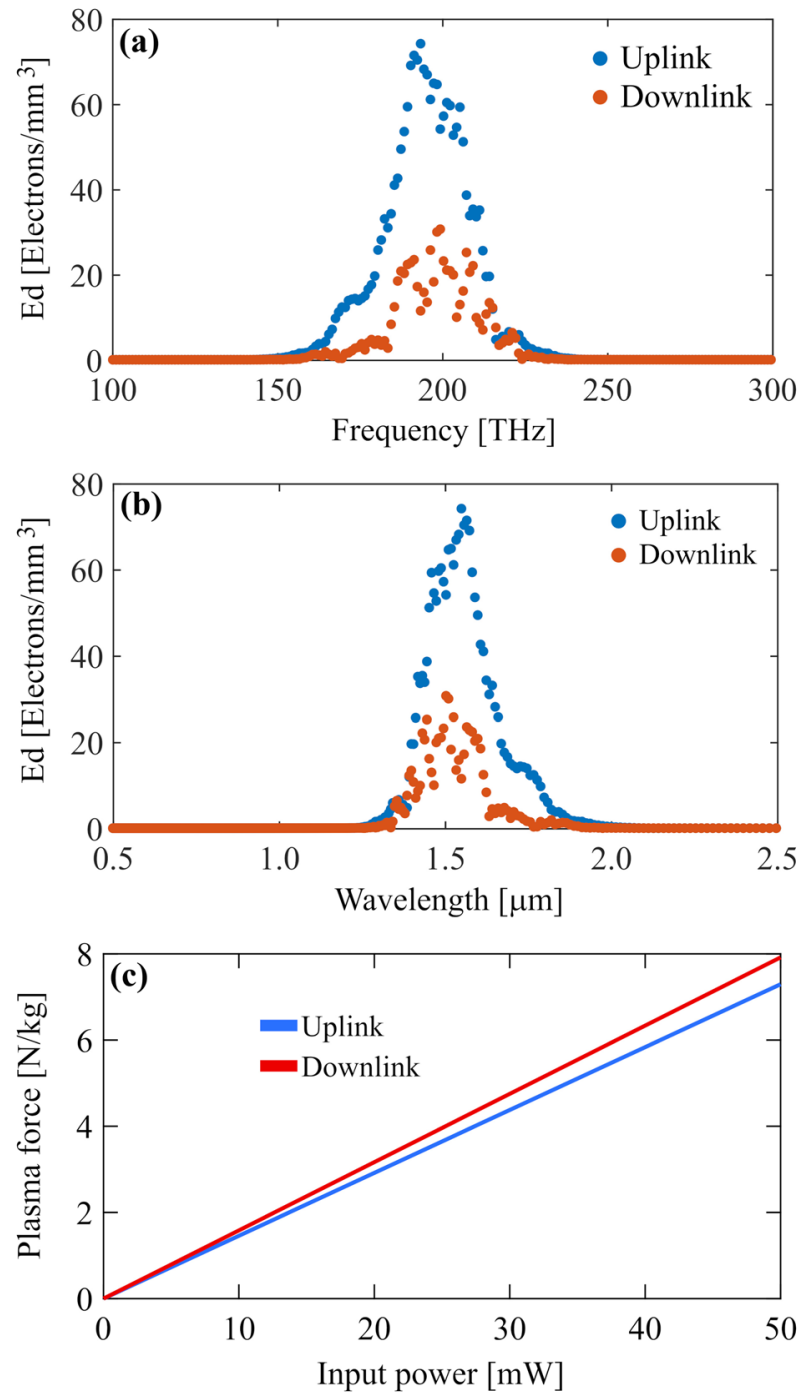

Fig. 6 The plot of dried spray station, where (a) frequency domain, (b) wavelength domain, the plasma frequency of $1.91 \times 10^{16} \mathrm{rads}^{-1}$ and $1.99 \times 10^{16} \mathrm{rads}^{-1}$ are obtained, respectively, for the uplink and downlink nodes, (c) plasma force where the sensitivity of $0.14 \mathrm{~N} \mathrm{~kg}^{-1} \mathrm{~mW}^{-1}$ and $0.16 \mathrm{~N} \mathrm{~kg}^{-1} \mathrm{~mW}^{-1}$ are obtained, respectively, for the uplink and downlink sensor nodes

near the registration. A moving robot (vehicle) in a hospital can be applied and controlled by the integrated sensors, which can connect with force sensors and the $\mathrm{LiFi}$ network for COVID-19 surveillance. The big data capacity network can accommodate all input information such as machine learning, artificial intelligence, and braininspired computing, which can be implemented within the robot brain [12, 13, 16, 30, 31, 39-47].

Monitoring is a must for daily care of ICU patients. Key factors for enhancing patient survival are optimization of the patient's critical condition parameters. It is either manually or through a WiFi-based system. The 


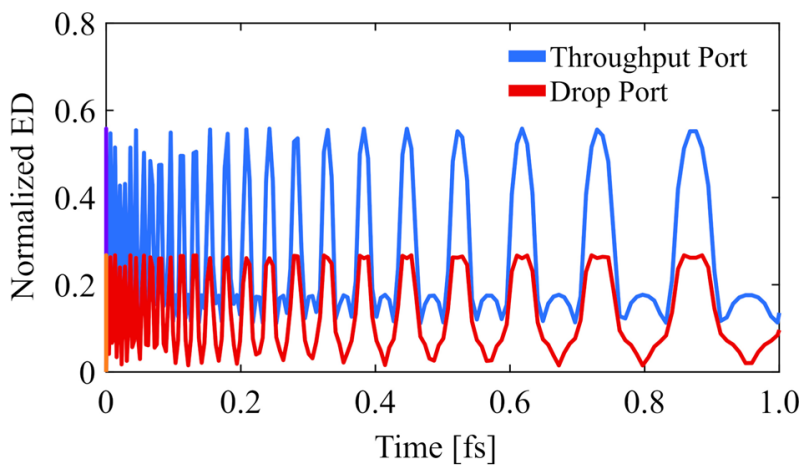

Fig. 7 The plot of the multiplexing signals to obtain the $40 \mathrm{Pbit} \mathrm{s}^{-1}$, the space-time function can be controlled by the modulated input into the add port. This function is applied with the COVID-19 communication mode, where the big data is the requirement

exponentially increased scalability reduces the speed of the WiFi-based system. In the light of this, LiFi traces the areas where WiFi is applicable with extra features of a high-speed data network. Other than the speed factor, LiFi suits better monitoring of the patient's conditions sans noninterference of frequency. Reducing the risk of being infected and spreading infection, the LiFi technology-based solutions can be blessings for the Medico and the supporting staff and also offer an effective live health data monitoring system.

Let us suppose the people are sitting in the waiting lounge of the hospital. Li-Fi is a point-to-point communication, where the LiFi is connected with the router. The $\mathrm{LiFi}$ is pointed in such a way that it covers the waiting lounge, where the beam will sense the presence of people (patients). The antenna beam can be adaptive, which will search in all areas of the waiting lounge and every

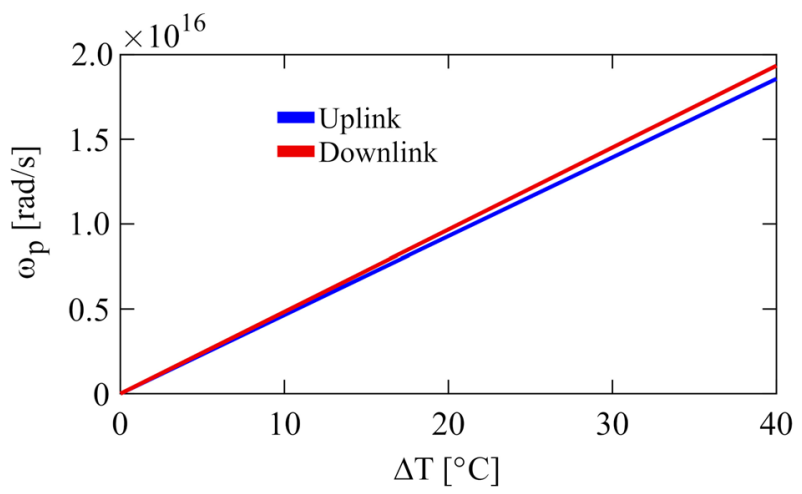

Fig. 8 The plot of plasma frequency shift and temperature change, where the sensitivity of $0.04 \mathrm{rads}^{-1}{ }^{\circ} \mathrm{C}^{-1}$ and $0.05 \mathrm{rads}^{-1}{ }^{\circ} \mathrm{C}^{-1}$ is obtained, respectively, for the uplink and downlink sensor nodes. The temperature sensor is applied with the COVID-19 surveillance mode room connected with LiFi. Hospital's mobile application
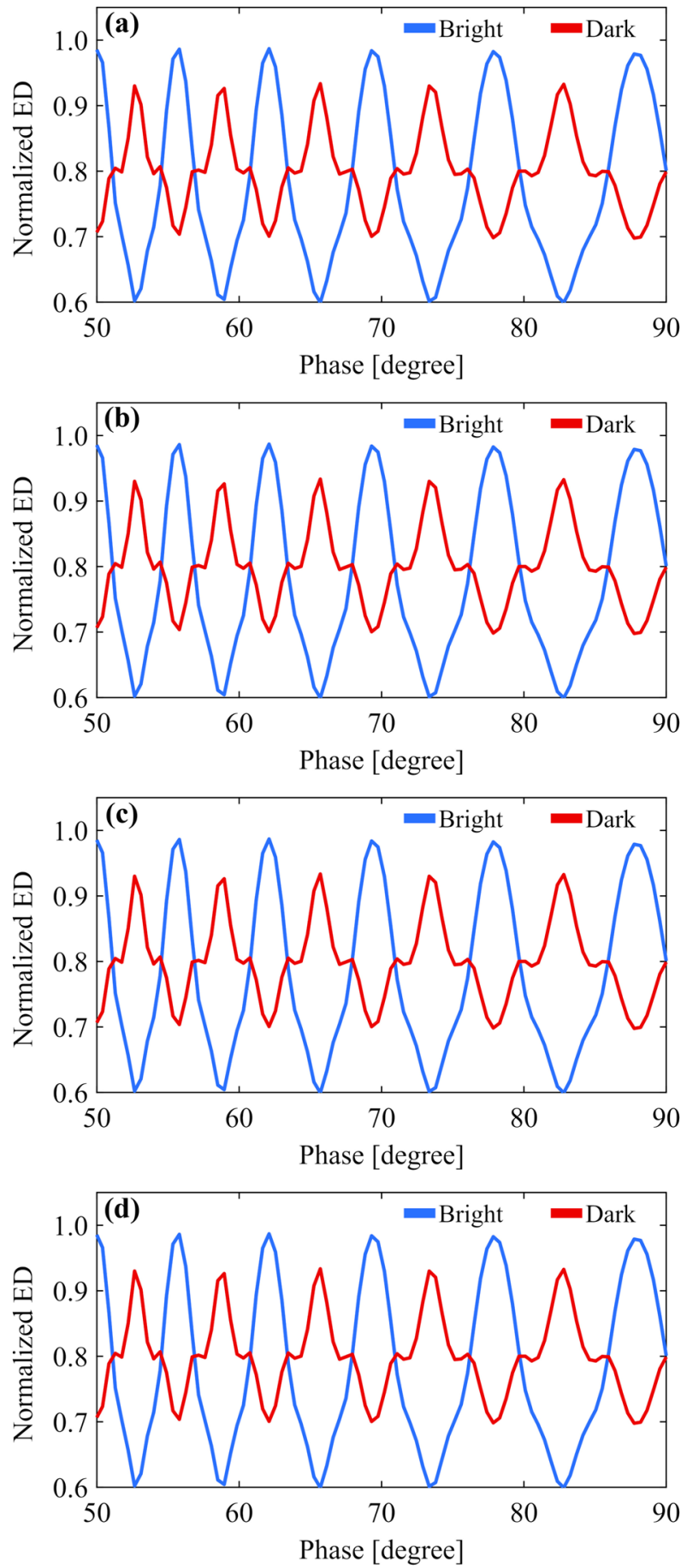

Fig. 9 The plot of the uplink and downlink quantum entanglements for quantum security applications, where (a) WiFi uplink entanglement, (b) WiFi downlink entanglement, (c) LiFi uplink entanglement, (d) where two WGMs are formed for uplink and downlink LiFi downlink entanglement. The polarized spin waves are formed by the trapped electron propagation, from which the polarized electrons (photons) can be configured by the output polarizing beamsplitters and detectors. The two-way communication can be formed by the up and downlink nodes, while the security codes can be confirmed by the information in the transmission line 
Fig. 10 COVID-19 surveillance in hospital using metamaterial antenna node LiFi network integration, where LiFi signals are optical wireless $(\mathrm{OW})$, UV: sterilizer, and infrared temperature (Inf), which can perform within the hospital and inside the ICU as shown in Fig. 9 (a) and (b), respectively. FLC: fuzzy logic controller. This is the indoor transmission link. However, the transmission link loss is included in the calculation

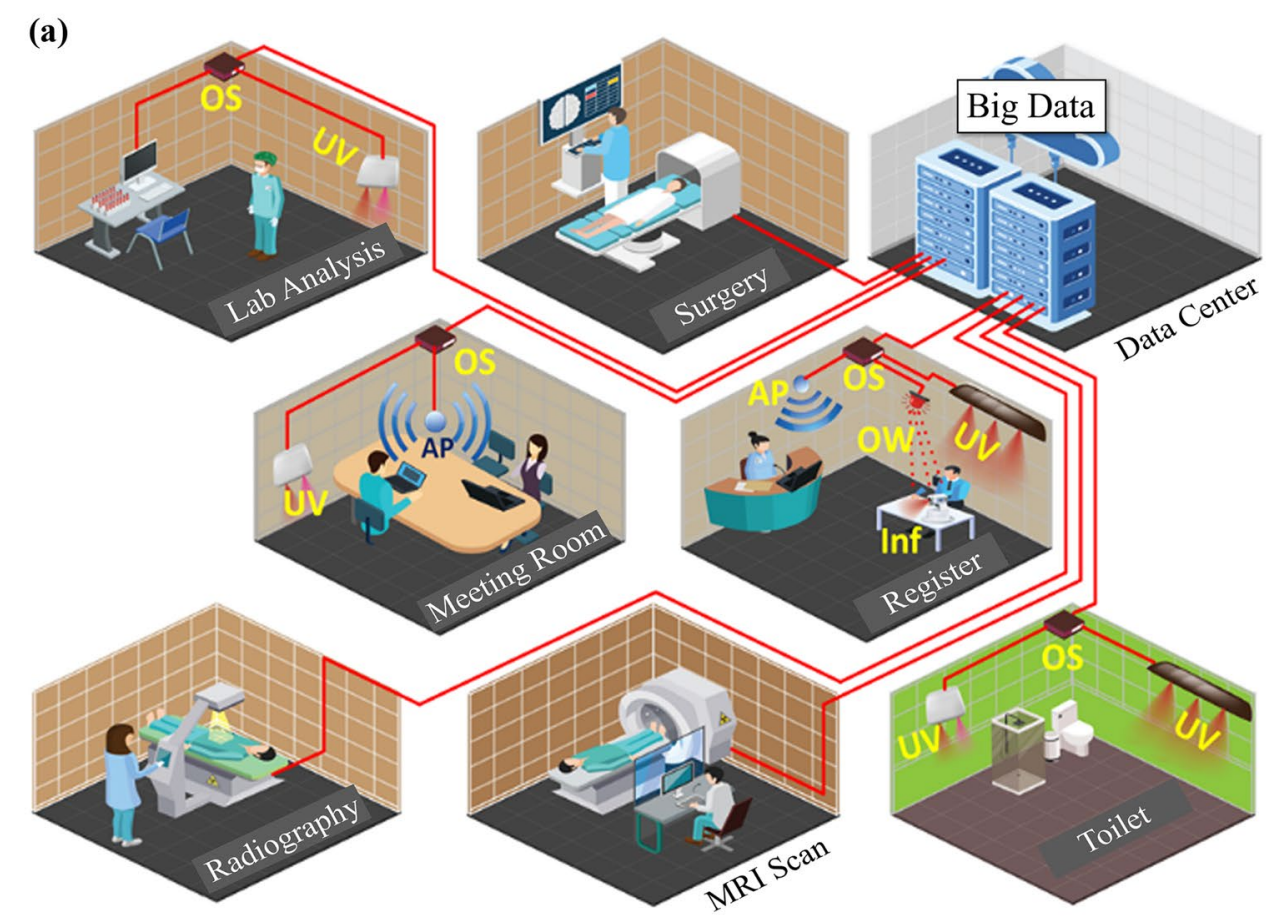
AP: Access Point
OS: Optical Switching
OW: Optical Wireless
UV: UV Sterilizer
InF: Infared Temperature

(b)

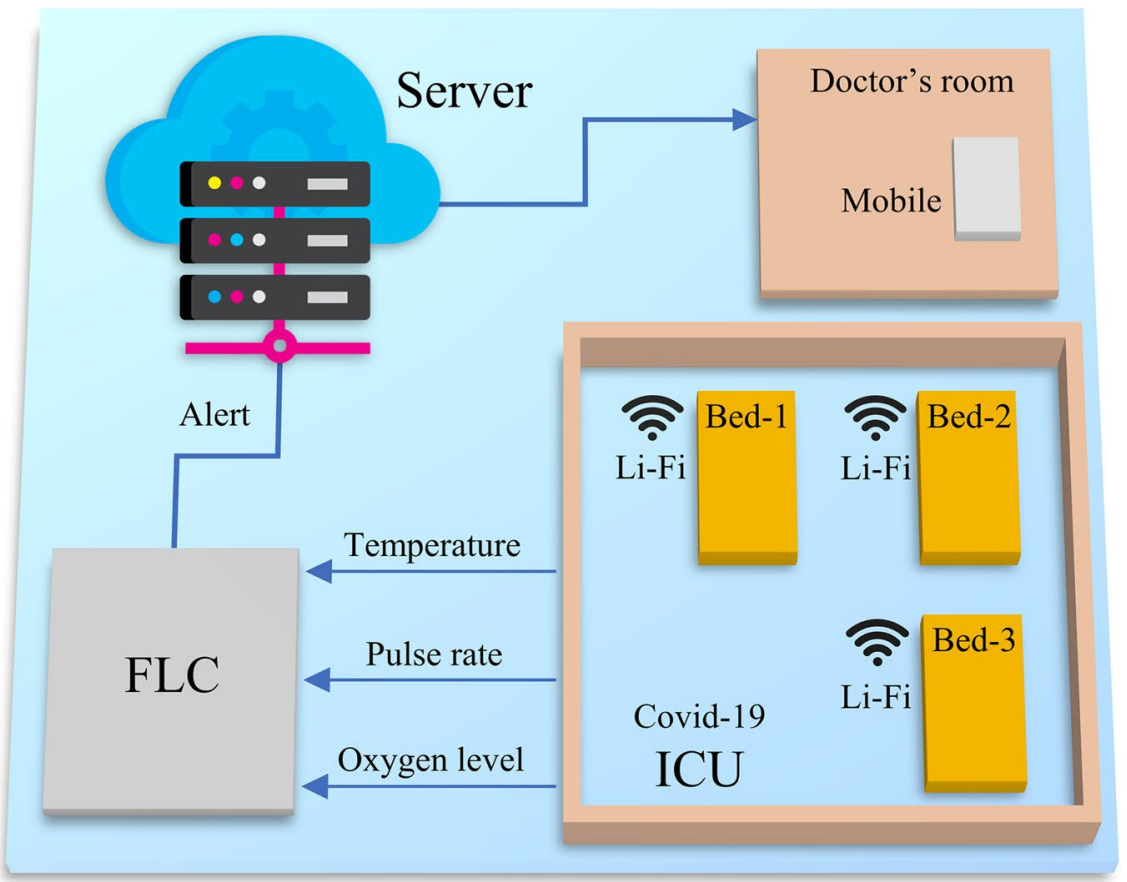

for COVID-19 is installed on the mobile phone of the patient. Patients visit other rooms like the cafeteria, billing counter, $\mathrm{x}$-ray room, the patients would be connected with the nearest available WiFi. The patient's position will be stored on the IP address of the LiFi nodes monitored inside the hospital. The designed system shown in Fig. 9 has applications in patient tracking and monitoring of patients inside ICU. A similar project has been implemented in the Surat Municipal Institute of Medical Education \& Research (SMIMER) Gujarat India [48]. It is a 
case study and explained in Fig. 10b. Let us consider a scene inside the ICU. There are three patient beds. The fuzzy system is designed based on the patient's condition parameters like oxygen level, pulse rate, and body temperature. The fuzzy logic-based system is presented for the patient's condition in the hospital as reported in [49], where the fuzzy rule base is designed using if-else. In this paper, three membership functions are defined for three input variables as oxygen level, heart rate (pulse), and temperature. Fuzzy if-else rules are provided by the following: the first patient's temperature is high, the 2nd and 3rd patient's pulse rate and oxygen levels, respectively, are normal, then the alert for patient one will be sent to the doctor. Similarly, other rules are defined. The output of the fuzzy decision system is given in Fig. 11. We suppose that the patient bed number 1 oxygen level goes down, then the LiFi connected with patient bed will send the low oxygen level to fuzzy logic control, then using LiFi server and a real-time app, the patient alert will be immediately sent on mobile app in doctor(nurse) room. The mobile app is installed with a patient app linked with $\mathrm{LiFi}$, as shown in Fig. 10b. Due to COVID-19, the doctors are very busy and need to avoid close proximity with the patients as much as possible. The proposed system would save the time and enhance the safety of the doctors. The rule-based system uses artificial management. The designed system has no EMI interference inside the hospital, which is a robust system. As shown in Fig. 10b, the mobile intensive care unit (ICU) can be installed in the vehicle for COVID-19 investigation and medication. All equipment can be linked with LiFi and the big data platform. High-speed imaging data transfer and real-time patient monitoring can be employed, which is capable of catering to more patients. The LiFi inside the hospital provides less EMI, in which the LiFi and big data platform provided the patients' data more secure.

Moreover, the contribution to the cognitive computation work can be configured as follows. The deep learning based on quantum consciousness can be performed by using the electron spin processing circuit embedded in the robot [45]. The quantum cellular automata processing can be retrieved and used. The 3D visual imaging using a microring embedded circuit and machine learning can be implemented in the robot brain [13, 39, 41, 45], which can be applied in the surveillance data. The daily detection of e-health within the hospital area can be monitored and useful for decision making $[13,50]$. The big data network can support the required applications [46].

There are several important points to justify the scheme.

1 The concept can be useful for the transmission of privacy preserving patient data.
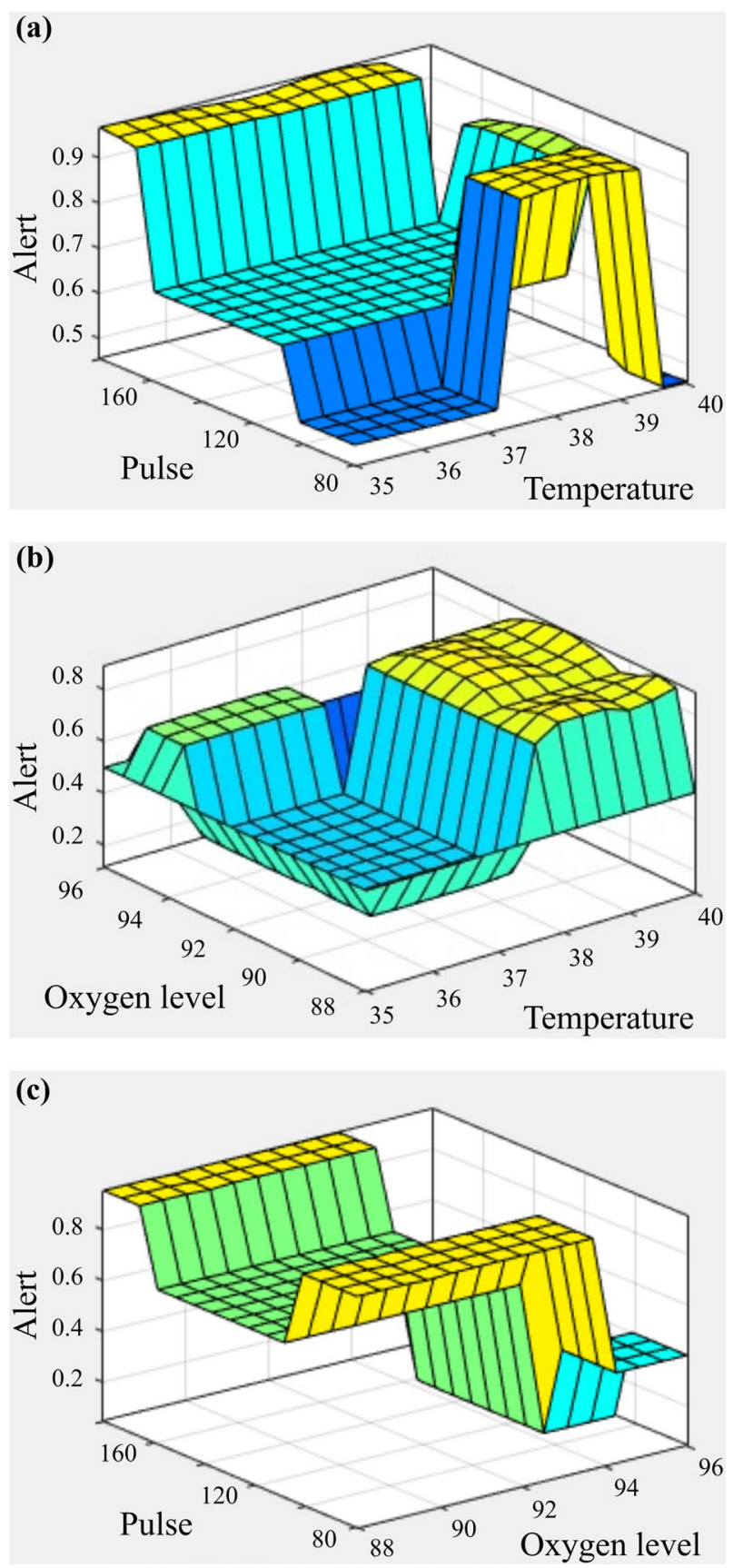

Fig. 11 Fuzzy decision system for alert of patients in ICU depending upon the fuzzy rules, the critical condition alert will be sent to the doctor(nurse), where (a), (b), and (c) are for pulse-temperature, oxygen level-temperature, and pulse-oxygen level monitoring alerts, respectively

2 System is avoiding any EMI with medical instruments as it uses LiFi. So it is a robust system.

3 Low latency, ultra high speed for hospital management using LiFi.

4 Fuzzy rule-based artificial management in hospital. 
5 Applications in COVID-19 patient tracking and monitoring in ICU.

This type of system has benefits in hospital surveillance and management as given in case study [48].

\section{Conclusion}

A microring embedded silver bar circuit is proposed to build $\mathrm{LiFi}$ sensor network nodes for the COVID-19 surveillance system. The system consists of MZI and panda ring resonator. The center ring consists of a silver $(\mathrm{Ag})$ metamaterial bar. When the light propagates, two WGMs are formed in both upper and lower microring resonators. These two WGMs work as uplink and downlink antennas for communication. The intensity plot in frequency, wavelength, and time domain is presented. The dried spray station results, for disinfectant, also plotted and discussed in frequency and wavelength domain. The spray is in the form of electron density. The obtained gains of uplink and downlink antennas are $4.95 \mathrm{~dB}$ and $1.28 \mathrm{~dB}$, while directivities are 16.22 and 12.55 for the uplink and downlink. The wider bandwidths are achieved using metamaterial antenna, the plasma frequency of $1.91 \times 10^{16} \mathrm{rads}^{-1}$ and $1.99 \times 10^{16} \mathrm{rads}^{-1}$ are obtained, respectively, for the uplink and downlink. The plasma force sensitivity of $0.14 \mathrm{~N} \mathrm{~kg}^{-1} \mathrm{~mW}^{-1}$ and $0.16 \mathrm{~N} \mathrm{~kg}^{-1} \mathrm{~mW}^{-1}$ are obtained, respectively, for the uplink and downlink. The temperature sensitivity of $0.04 \mathrm{rads}^{-1}{ }^{\circ} \mathrm{C}^{-1}$ and $0.05 \mathrm{rads}^{-1}{ }^{\circ} \mathrm{C}^{-1}$ are obtained, respectively, for the uplink and downlink. The bandwidth of $40 \mathrm{Pbits}^{-1}$ is obtained for big data transmission. The proposed system consists of plasmonic spray consisting of disinfectants for applications in COVID-19. Plasmonic sensors can be applied when the uplink and downlink communications using are functioned as the surveillance mode. Micro sensors to monitor the person's temperature and display on the screen. The medical data can be secured by quantum transmission supported by the LiFi network. Therefore, the proposed LiFi-integrated network is a suitable candidate for COVID-19 surveillance in hospitals. Apart from the surveillance work, the main contribution of this work is the e-health applications, which can be connected to the community by the long-haul network. The medical information can be secured and transmitted to the required destinations. A fuzzy logic-based system incorporates big data that is suitable for COVID-19 surveillance and management in hospitals.

In the future, computations in artificial intelligence will be developed by the use of light instead of electricity. This would not drastically improve the speed of computation but also the efficiency of machine learning. Presently, the more intelligent is the task, the more the power is required for the processors. Photonbased neural network processing unit will overcome these shortcomings to a considerable extent. Our designed system will integrate well with the future trend of intelligent communication.
Acknowledgments One of the authors (A. Garhwal) would like to acknowledge the research facilities provided by Ton Duc Thang University.

Authors Contribution This work was carried out in close collaboration between all co-authors. P.Yu and K.R defined the research theme and contributed an early design of the system. A.G. further implemented, refined the system development and made the first draft. M.B. improved graphics. A.E.A. improved the results. P.Yo validated, compared Optiwave and Matlab results. S.S. reviewed and polished english. All authors wrote the paper. All authors have contributed to, seen and approved the final manuscript.

Funding This research is funded by the Foundation of Science and Technology Development of Ton Duc Thang University (FOSTECT), website: http://fostect.tdtu.edu.vn, under the research grant number FOSTECT.2017.BR.07.

\section{Compliance with Ethical Standards}

Conflict of Interest The authors declare that they have no conflict of interest.

Ethical Approval This article does not contain any studies with human participants or animals performed by any of the authors.

Informed Consent Informed consent was obtained from all individual participants included in the study.

\section{References}

1. World Health Organization (WHO). Novel coronavirus. https://www. who.int/emergencies/diseases/novel-coronavirus-2019. Accessed $1^{\text {st }}$ July 2020.

2. Yu J, Qiao S, Guo R, Wang X. Cryo-EM structures of HKU2 and SADS-CoV spike glycoproteins provide insights into coronavirus evolution. Nat Commun. 2020;11(3070):1-12.

3. Chen B, Tian EK, He B, Tian L, Han R, Wang S, et al. Overview of lethal human coronaviruses. Signal Transduct Target Ther. 2020;5(89):1-16.

4. Duarte PM, Santana VTPde. Disinfection measures and control of SARS-COV-2 transmission. Global Biosecurity. 2020;1(3).

5. Buonnano M, Welch D, Shuryak I, Brenner DJ. Far-UVC light $(222 \mathrm{~nm})$ efficiently and safely inactivates airborne human coronaviruses. Sci Rep. 2020;10(10285):1-8.

6. Xiao K, Zhai J, Feng Y, Zhou N, Zhang X, Zou JJ et al. Isolation of SARS-CoV-2-related coronavirus from Malayan pangolins. Nature. 2020; 1-18.

7. Tay MZ, Poh CM, Renia L, MacAry PA, Ng LFP. The trinity of COVID-19: immunity, inflammation and intervention. Nat Rev Immunol. 2020;2020(20):363-74.

8. Seah I, Su X, Lingam G. Revisiting the dangers of the coronavirus in the ophthalmology practice. Eye. 2020;34:1155-7.

9. Rabenau HF, Kampf G, Cinatl J, Doerr HW. Efficacy of various disinfectants against SARS coronavirus. J Hosp Infect. 2005;61(2):107-11.

10. Meng L, Hua F, Bian Z. Coronavirus disease 2019 (COVID-19): emerging and future challenges for dental and oral medicine. J Dent Res. 2020;99(5):481-7.

11. Ather A, Patel B, Ruparel NB, Diogenes A, Hargreaves KM. Coronavirus diseases 19 (COVID-19): implications for clinical dental care. J Endod. 2020;46(5):584-95.

12. Youplao P, Sarapat N, Pornsuwancharoen N, Chaiwong K, Jalil MA, Amiri IS, et al. Plasmonic op-amp circuit model using the 
inline successive microring pumping scheme. Microsyst Technol. 2018;24:3689-95.

13. Bunruangses M, Youplao P, Amiri IS, Pornsuwancharoen N, Punthawanunt S, Singh G, et al. Microring distributed sensors using space-time function control. IEEE Sens J. 2020;20(2):799-805.

14. Garhwal A, Ray K, Arumona AE, Bharti GK, Amiri IS, Yupapin P. Spin-wave generation using MZI embedded plasmonic antenna for quantum communications. Opt Quant Electron. 2020;52(241):1-12.

15. Arumona AE, Amiri IS, Yupapin P. Plasmonic micro-antenna characteristics using gold grating embedded in a panda-ring circuit. Plasmonics. 2020;2020(15):279-85.

16. Arumona AE, Amiri IS, Punthawanunt S, Yupapin P. High density quantum bit generation using microring plasmonic antenna. Opt Quant Electron. 2020;52(208):1-12.

17. Otter JA, Donskey C, Yezli S, Douthwaite S, Goldenberg SD, Weber DJ. Transmission of SARS and MARS coronaviruses and influenza virus in healthcare settings: the possible role of dry surface contamination. J Hosp Infect. 2016;92:235-50.

18. Deshmukh SP, Patil SM, Mullani SB, Delekar SD. Silver nanoparticles as an effective disinfectant: a review. Mater Sci Eng: C. 2019;97:954-65.

19. Bashir S, Chamakura K, Perez-Ballestero R, Luo Z, Liu J. Mechanism of silver nanoparticles as a disinfectant. Int J Green Energy. 2011;3(2):118-33.

20. Ding $\mathrm{H}$. Application and design of patient temperature acquisition system based on wireless sensor network. Int J Online Biomed Eng. 2017;13(5):18-28.

21. Geng Y, Li X, Tan X, Deng Y, Yu Y. High-sensitivity Mach Zehnder interferometric temperature fiber sensor based on a waistenlarged fusion bitaper. IEEE Sens J. 2011;11(11):2891-4.

22. Geng Y, Li X, Tan X, Deng Y, Yu Y. Compact and ultrasensitive temperature sensor with a fully liquid-filled photonic crystal fiber Mach-Zehnder interferometer. IEEE Sens J. 2014;14(1):167-70.

23. Alexandru AG, Radu IM, Bizon ML. Big data in healthcare-opportunities and challenges. Informatica Economica. 2018;22(2):43-54.

24. Dash S, Shakyawar SK, Sharma M, Kaushik S. Big data in healthcare: management, analysis and future prospects. J Big Data. 2019;6(54):1-25.

25. Pires P, Mendes L, Mendes J, Rodrigues R, Pereira A. Integrated e healthcare system for elderly people. Cognitive Computing. 2015;8:368-84.

26. Price WN, Cohen IG. Privacy in age of medical big data. Nat Med. 2019;25(1):37-43.

27. Liu S, Liu W, Guo G, Cai B, Liu X. Cryptanalysis of controlled bidirectional quantum secure direct communication network using classical XOR operation and quantum entanglement. IEEE Commun Lett. 2017;21(10):2202-5.

28. Song S, Hayashi M. Secure quantum network code without classical communication. IEEE Trans Inf Theory. 2019;66(2):1178-92.

29. Abd El-Latif AA, Abd-El-Atty B, Talha M. Robust encryption of quantum medical images. Special Section on Mobile Multimedia for Health Care, IEEE Access. 2018; 6: 1073-81.

30. Arumona AE, Garhal A, Punthawanunt S, Ray K, Youplao P, Yupapin P. Micro-metamaterial antenna characteristics using microring embedded silver bars. Microsyst Technol. 2020; $1-4$.

31. Arumona AE, Garhwal A, Youplao P, Amiri IS, Ray K, Punthawanunt $S$ et al. Electron cloud spectroscopy using microring Fabry-Perot sensor embedded gold grating. IEEE Sensors Journal. 2020;20(18):10564-71.
32. Phatharacorn $\mathrm{P}$, Chiangga S, Yupapin P. Analytical and simulation of a triple micro whispering gallery mode probe system for a 3D blood flow rate sensor. Appl Opt. 2016;55:9504-13.

33. Mirmira SR, Fletcher LS. Review of the thermal conductivity of thin films. J Thermophys Heat Trans. 1998;12(2):121-31.

34. OptiFDTD Technical Background and Tutorials (Finite Difference Time Domain) Photonics Simulation Software, Version 12.0. http://www.optiwave.com, Searched on $20^{\text {th }}$ May, 2020.

35. Garhwal A, Arumona AE, Ray K, Youplao P, Suwandee S, Yupapin P. Microplasma source circuit using microring spacetime distortion control. IEEE Transactions on Plasma Science. 2020;48(10):3600-5.

36. Young HD. Universityphysics, $11^{\text {th }}$ Ed. USA: AddisonWesley Publishing Company; 2006.

37. Babar $\mathrm{S}$, Weaver JH. Optical constants of $\mathrm{Cu}, \mathrm{Ag}$, and Au revisited. Appl Opt. 2015;54(3):477-81.

38. Pornsuwancharoen N, Amiri IS, Suhailin FH, Aziz MS, Ali J, Singh G, et al. Micro-current source generated by a WGM of light within a stacked silicon-graphene-Au waveguide. IEEE Photonics Technol Lett. 2017;29(21):1768-71.

39. Bunruangses M, Youplao P, Amiri IS, Pornsuwancharoen, Yupapin P. Double vision model using space-time function control within silicon microring system. Silicon. 2019; 1-6.

40. Kibira MG, Nguyen K, Villardi GP, Zhao O, Ishizu K, Kojima F. Big data analytics, machine learning and artificial intelligence in next generation wireless networks. IEEE Access. 2018;6:32328-38.

41. Tamee K, Yupapin P. Psychiatric investigation using WGMs in microring circuits. J Innov Opt Health Sci 2013;6(4), 1350004-1-7.

42. Bunruangses M, Youplao P, Amiri S, Pornsuwancharoen, Yupapin P. Double vision model using space-time function control within silicon microring system. Silicon, 2019; 1-6.

43. Bunruangses M, Chaiwong K, Amiri IS, Youplao P, Pornsuwancharoen N, Yupapin P. High-density wavelength multiplexing model for THz-EMI transmission. Wirel Pers Commun; 2020;1-6.

44. Arumona AE, Amiri IS, Yupapin P. Plasmonic microring-antenna characteristics using gold grating embedded in a Panda-ring circuit. Plasmonics. 2019;15:279-85.

45. Youplao P, Pornsuwancharoen, Amiri IS, Ali J, Grattan KTV. Microring stereo sensor model using Kerr-Vernier effects for biocell sensor and communication. Nano Communication 2018; 17: 30-35.

46. Bunruangses M, Sunat K, Mitatha S, Yupapin. Vehicular ad hoc network for a surveillance system using multifrequency band enhancement. Opt Eng 2010; 49: 095001.

47. Bunruangses M, Arumona AE, Youplao P, Pornsuwancharoen N, Ray K, Yupapin P. Modeling of a superconducting sensor with microring-embedded gold-island space-time control. Journal of Computational Electronics. 2020;19:1678-84.

48. https://www.medicircle.in/nav-wireless-providing-lifi-technologyhealthcare-sector/ Accessed $11^{\text {th }}$ July 2020.

49. Al-Dmour JA, SagahyroonAssim, Al-Ali Ar, Abusnana Salah, A fuzzy logic-based warning system for patient classification. Health Inform J. 2019;25(3):1004-24.

50. Belmonte-Fernandez O, Caballer-Miedes A, Chinellato A, Montoliu E, Sansano-Sansano E, Garcia-Vidal R. Anomaly detection in activities of daily living with linear drift. Cognitive Computation. 2020;12:1233-51. 


\section{Affiliations}

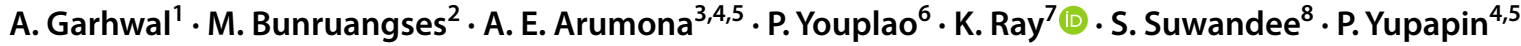

A. Garhwal

anitagarhwal@gmail.com

1 Amity School of Engineering \& Technology, Amity University Rajasthan, Jaipur 303002, India

2 Department of Computer Engineering, Faculty of Industrial Education, Rajamangala University of Technology Phra Nakhon, Bangkok 10300, Thailand

3 Computational Optics Research Group, Advanced Institute of Materials Science, Ton Duc Thang University, District 7, Ho Chi Minh City, Vietnam

4 Faculty of Applied Sciences, Ton Duc Thang University, District 7, Ho Chi Minh City, Vietnam
5 Division of Computational Physics, Institute for Computational Science, Ton Duc Thang University, District 7, Ho Chi Minh City, Vietnam

6 Department of Electrical Engineering, Faculty of Industry and Technology, Rajamangala University of Technology Isan Sakon Nakhon Campus, Sakon Nakhon 47160, Thailand

7 Amity School of Applied Sciences, Amity University Rajasthan, Jaipur 303002, India

8 Kasem Bundit University, Bangkok 10250, Thailand 